\title{
Editorial: Systematics, Darwinism, and the Philosophy of Science
}

\author{
Francisco Vergara-Silva $\cdot$ Rasmus Grønfeldt Winther
}

Received: 9 March 2009/Accepted: 9 March 2009/Published online: 3 April 2009

(C) Springer Science+Business Media B.V. 2009

This special issue of Acta Biotheoretica grows out of a small conference on "Systematics, Darwinism, and the Philosophy of Science" held at the Universidad Nacional Autónoma de México (UNAM) in the Fall of 2006. We asked the conference attendees and other experts to submit papers exploring issues emerging around contemporary biological systematics and Darwinism. Following common usage, we construe systematics as the research field engaged in classifying and naming organisms; we understand Darwinism (roughly: evolutionary biology), as the set of disciplines that provide historical, selective, and perhaps other types of explanations for the origin and nature of parts and characters (from geneticmolecular to behavioral-cognitive) of hierarchically arranged taxa. We are extremely grateful to the 12 authors, who exhibit a broad range of deep expertise and creativity, in both biological and philosophical matters. In order to publish this large number of contributions, we divide them into two groups: "From a Philosophical Point of View" and "From a Biological Point of View." Each grouping includes a general introduction.

The articles display a rich diversity of positions on systematics and Darwinism. Moreover, they vary tremendously in how they imagine the conceptual, methodological, and historical interaction between systematics and Darwinism. Specific questions addressed here include: What is the appropriate relation between classification (grouping) and taxonomy (naming)? Is phylogenetic inference fundamentally (and without remainder) abductive, deductive, or inductive? How can an epistemological, rather than a metaphysical, emphasis on natural kinds shed

\footnotetext{
F. Vergara-Silva

Laboratorio de Sistemática Molecular (Jardín Botánico), Instituto de Biología, Universidad Nacional Autónoma de México, Mexico city, Mexico

R. G. Winther $(\bowtie)$

Philosophy Department, University of California, Santa Cruz, 1156 High St,

Santa Cruz, CA 95064, USA

e-mail: rgw@ucsc.edu; rgwinther@gmail.com
} 
light on actual morphological structure and evolutionary process? Need we endorse a priori any particular model of evolutionary process in order to classify and name biological units (e.g., varieties, species, and higher-level taxa)? Is the Tree of Life a real entity, an instrumental model, or a metaphor? What exactly is Darwinism, and is it co-extensive with evolutionary biology? What kind of thing is a biological species? How can we complement selective, historical and other types (e.g., structuralist) of evolutionary explanations?

We believe that in the context of the "Darwin Year" celebrations taking place worldwide in 2009, and at a time when crucial fields such as biodiversity discovery and conservation and systems biology turn increasingly data-driven, it would be fruitful to take a step back and consider the general issues addressed in the articles here compiled. The philosophy of science can be productively used to investigate systematics, Darwinism, and their interface. The hope is to further the development of methodologically, conceptually and even ethically sophisticated models, theories, and practices useful for the sciences that aim to catalog, comprehend, and construct life.

From its inception, every academic project is incomplete. We feel that it would be dishonest not to mention important fields of inquiry that we, unfortunately, had to bracket. Although the contributions are rich in philosophical subtlety and biological insight, there are no explicitly historical or sociological investigations of the theories and practices of systematics and Darwinism. Such "contextual" work can itself productively feedback on philosophical and biological "content" investigations, as some of the contributors to this special issue also note. Permit us to point to two tropes that could be investigated in order to remedy this lacuna: the colonial setting of natural history and "The Essentialism Story."

As a Western cultural product, systematics emerges out of natural history. A detailed knowledge of the taxonomic diversity of many groups of organisms was essential to the work of Linnaeus, Buffon, and Darwin, among others. Interestingly, their knowledge production projects-i.e., their classifications, and their theories and methods of classification-were intricately tied to colonial discovery and conquest. After all, one of the many consequences of colonialism was the collection of dead and living species from all parts of the globe, including the Americas, South Pacific, Indian Subcontinent, and sub-Saharan Africa; these samples were deposited in safe havens in the colonial capitals, especially London and Paris. Such spoils served the great students of natural history well. History never ends. In 2009, globalization continues and the centers of power increase in number and geographic-cultural diversity. In the context of this increasing interconnectivity, scientific efforts explicitly related to systematics and Darwinism, such as species barcoding, biodiversity cataloging, and human genome diversity data-mining, serve as testimony for the continued colonial imperative of lording over all kinds of life in the Periphery. Are these efforts of "postcolonial biology" indeed a manifestation of the same imperative? If so, how might engaged biologists and philosophers help build a fairer and kinder system of power relations?

Ernst Mayr, Michael Ghiselin, and David Hull entrenched a standard historiography of Darwin's role in systematics: Darwin was a variational, population thinker who liberated us from essentialist, typological thinking. According to these distinguished authors, everyone before Darwin, especially Linnaeus, held that each 
biological species was characterized by intrinsic, definitional Aristotelian essences. Such species-level essences were taken to explain the immutability of species and the static order of the Natural System. This well-known historiography-sometimes called "The Essentialism Story" - has recently been critically analyzed by Ronald Amundson, Gordon McOuat, and Mary Winsor. The historically and sociologically sophisticated work of these scholars belies over-simplified assumptions about an ubiquitous pre-Darwin(ian) metaphysical essentialism. Their analyses show the rich context and varied assumptions, practices, and concepts surrounding such central notions as species, natural kinds, types, and change. The Essentialism Story turned out to be a fiction. Again, the complex nature of actual historical and social processes cannot be suppressed once we open what some might consider the multilingual Pandora's Box of the historical archives and lengthy and esoteric alreadypublished works. Further historical and sociological investigations-especially by younger undergraduate, masters, and doctoral students-would undoubtedly be welcomed by those of us interested in systematics and Darwinism.

We are extremely grateful to a number of people and institutions for their support. The Instituto de Investigationes Filosóficas (IIF-UNAM) and the Graduate Program in Philosophy of Science, chaired by, respectively, Guillermo Hurtado and Atocha Aliseda kindly provided financial assistance for the initial conference. Additional financial resources were made available by Lilia Espinosa and Juan Núñez Farfán at the Programa de Posgrado en Ciencias Biológicas, UNAM. Lucía Anaya, Bryan de la Torre, Margarita Muñiz, and Noemí Reyes of the IIF-UNAM tirelessly offered administrative and technical support. Sergio Martínez and Carlos López Beltrán made helpful suggestions of an academic nature. Thomas Reydon patiently provided editorial assistance and suggestions every step of the way. Finally, we reiterate our sincere gratitude to the contributors, not only for their ideas, but also for their generous cooperation and unfailing, friendly support. ¡Muchas gracias a todos ustedes! 